\title{
THE DEAN'S ROLE IN FOSTERING COLLABORATIVE,
}

\section{MULTI-DISCIPLINARY RESEARCH}

\author{
Sally Frost Mason \\ Dean of Liberal Arts \& Sciences \\ Professor of Molecular Biosciences \\ University of Kansas
}

Two years ago at these gatherings, I stressed the point that a dean's role is to act as a facilitator-a facilitator of the faculty, staff, and students that comprise the school or college that he/she is administering. Indeed, facilitation becomes even more important to a dean when the topic turns to research. Few deans can maintain a full research program, teach, and still serve as the administrative "leader" of one or more units. At the University of Kansas (KU), like many other public research institutions, the College of Arts and Sciences is a large and diverse collection of more than 50 departments and programs spanning the humanities, social and behavioral sciences, and natural sciences and mathematics. As a dean, formerly engaged in independent research as a life scientist for many years, the transition to administration has meant a change in focus of the types of scholarly activities that I can conduct myself. More and more, I find I take great and vicarious pleasure in the research and teaching accomplishments of the many colleagues who are part of an operation that includes nearly half of all tenuretrack faculty on our campus. The opportunities for a dean to exercise skill at facilitation are thus numerous and limited only by resources and imagination.

Within the College of Arts and Sciences at $\mathrm{KU}$, there are several examples of collaborative, multi-disciplinary efforts that the dean and other administrators have helped facilitate and grow. Of the two examples listed below, the first is an example of a research/outreach/grant-driven set of activities that are models for developing programs across disciplinary boundaries, particularly within the humanities and social sciences. The second example, also research grant-driven, is a much newer set of activities within the sciences that has great potential for fostering true collaborations across the disciplines of the biological, physical, and mathematical sciences.

\section{Area/International Studies Programs}

$\mathrm{KU}$ has been the beneficiary of a number of Department of Education Title VI National Resource Center (NRC) grants for a number of years. Currently, Russian and East European Studies (REES), Latin American Studies (LAS), and East Asian Studies (EAS) are all funded as NRC's, and African Studies has been funded in the past. The first step in preparing to become an NRC involves formation of a center and appointment of a center director, who is also the principal investigator on the grant. Once formed, the 
center continues to function using both grant monies obtained and internal resources committed to help fund the goals of the center as outlined in the grant. To be successful in the funding arena, the center must establish that it has sufficient expertise in the language, culture, politics, economics, etc. of a particular region of the world (or plans to acquire that expertise to complement existing strengths). This has meant quite often that faculty need to be added across a multiplicity of departments who would then contribute dually to the center (program) and department.

Collaborations evolve at many levels because of these centers. For example, the center director, well before the grant or grant renewal is to be submitted, begins to plan by examining what, if any, areas of expertise might need to be enhanced in order to support the case to be made for the grant. The director early on begins discussion with the relevant departments about the potential for mutually beneficial faculty hires. Then, once these partnerships have formed, the needs are brought to the dean's office and prioritized with other hiring requests that have been made by College administrators. The fact that priorities such as these bear the endorsement of at least two units usually situates them advantageously for high priority. Moreover, the grant will usually pay a portion of the salary for these positions for a period of years with the understanding that at the end of two or three years, the institution assumes full responsibility for this expense. This type of arrangement can be extremely attractive administratively, either as a method for generating some salary savings ("shrinkage") that can be used to support infrastructure on a temporary basis or as a means of affording a new faculty hire sooner, rather than later, as base salary dollars become available. Consequently, REES, for example, has faculty partners in more than a dozen different departments that span the entire range of divisions across the College.

Although NRC's are not models unique to Kansas, I have discovered that few institutions are as successful or as aggressive as we have been in brokering joint appointments. Indeed, many of the faculty affiliated with these centers have joint appointments-a 0.5 FTE tenured or tenure-track appointment in a department and (usually) 0.5 FTE appointment within a center. We have been doing these for many years across many units within the College, and with other schools and, as a result, the fears that often accompany a pre-tenure joint appointment are minimal and often unfounded. Part of this success is due to a clearly written joint appointment agreement document that is shared with all parties at the time of appointment, and a faculty contract written in such a way as to guarantee, as much as possible, that work relevant on both sides of the appointment is taken seriously. Here again, a dean can work to ensure that the college-level promotion and tenure committee gives full credit for the work done by faculty appointed jointly. 
Not only do the NRC's create opportunities for faculty collaboration on research, but each center has as part of its funded mission an outreach component. Outreach may be into the local schools or it may extend into the international communities that the NRC's represent. Usually, both types of outreach are ongoing through the centers at any given time. By sending into classrooms across Kansas KU faculty and staff who are knowledgeable about Russia or Latin America or Africa, we employ a potent tool for stimulating young minds to think globally. A stellar example of the influence that an NRC can have within a state was most obvious several years back when an international exhibit, "Treasures of the Czars," was brought to Topeka, Kansas. The number of visitors to this exhibit from all over the Midwest was phenomenal, and the exhibit itself was presented and marketed with help from REES faculty and staff here at KU.

The NRC and other area studies centers at KU have been in existence for well over a decade now and provide outstanding examples of how collaborative, multi-disciplinary research can be developed and maintained. The road has not always been smooth for each of these centers and their strength depends to some degree on the talent and determination of their directors, but their overall success as models of collaborative effort is undeniable.

\section{A Model for the Sciences-EPSCoR}

When first introduced into the state of Kansas nearly 10 years ago, many of us recognized the potential of the National Science Foundation's version of the Experimental Program to Stimulate Competitive Research (EPSCoR) and believed it would stimulate collaboration and multi-disciplinary research in the "hard" sciences, particularly physics and chemistry. The initial NSF award totaled approximately $\$ 4.5$ million over 5 years, and was matched at least dollar for dollar by money from the state and institutions. The state program director and principal investigator on this grant had some discretion in how the money would be spent, but primarily it was to be committed to a series of large, multi-year, multi-investigator projects, with lesser amounts committed to stimulating smaller (often pilot) projects that met the objectives of the EPSCoR program.

Indeed the first systemic initiatives undertaken in Kansas were successfully funded only if they involved cross-institutional collaborations and/or evidence of inter-institutional cross-disciplinary activities. Senior faculty put together "groups" consisting of junior faculty, post-doctoral fellows, graduate students and undergraduates with plans to conduct hierarchical levels of mentoring down through the entire chain of participants. Some of these efforts were indeed successful in garnering new opportunities for faculty hires, for enhancing the graduate programs, and for improving overall infrastructure at KU, Kansas State University and Wichita State University, 
the three participants in the statewide EPSCoR program. The groups were focused around common faculty interests across the institutions, for example, developmental genetics, chaos theory, materials synthesis, and others. The money provided by the grant was to be used primarily to enhance the research opportunities of the younger faculty, improve infrastructure generally, and stimulate interactions among the group participants.

Early on, it was gratifying to see the collaborations develop. Over time, however, it has become clear that junior faculty, in particular, believe (justifiably so) that their long-term success, i.e., tenure, will be judged not so much by collaboration and collaborative work, but by the independent efforts they themselves have undertaken. In some cases, EPSCoR was the springboard for this success, but more often than not, collaboration would be viewed as competition, and success in this competition meant going out on your own to bring in more money.

Indeed, in recent years, during the tenure of the second five-year contract from the NSF, increasingly more funds have been committed over time to junior faculty in the form of "first" awards. For these, there is no requirement of collaboration or mentorship by a senior faculty member to compete for first awards; there is only the necessity of writing and submitting an NSF grant through the normal channels while at the same time submitting to EPSCoR for a first award.

The good news is that this has worked quite well. Grant productivity overall has increased at the university and young science faculty are having significant success in competing for federal funding. First awards have helped in a number of cases; in just as many, first awards were not needed as a prelude to success in the funding arena.

What role has a dean played in all of this? While still associate dean, I was able to serve as co-principal investigator on the NSF award and thus as associate project director for the statewide initiatives. I worked closely with the project director, Ted Kuwana, who has been instrumental in bringing talent, resources, and a healthy collaborative viewpoint to the state. He has made tremendous contributions to improving science across the state of Kansas and improving the stature of Kansas with federal agencies like the NSF.

My own enthusiasm for the collaborations that were established through EPSCoR was high, and the contract submitted at that time reflected the collective enthusiasm of many of us for these opportunities. Shortly after receiving the notice of award, I became interim dean, and my level of direct participation has fallen significantly over the past few years as a result of new responsibilities and concerns about conflict of interest. Still, the willingness to commit new faculty lines, start-up monies and matching dollars for major 
equipment and infrastructure have all come through the dean's office, and I take vicarious pleasure once again in the successes of our faculty and students who have benefited from EPSCoR. I can also reflect on where we've been thanks to EPSCoR and how this model has worked in the context of the highly successful NRC's mentioned in the preceding section.

\section{Where are We Now?}

In spite of good efforts made through the EPSCoR initiative and other federal grants that encourage large-scale collaborations locally and nationally, the sciences, and thus scientists, still tend for the most part to think and act as independent contractors. There are of course notable exceptions to this, especially in physics and math, where huge consortia of faculty working in theoretical and particle physics or chaos theory are the norm. But, for the purposes of rewards, groups in science tend to build around individual investigators who may themselves be surrounded by graduate students, postdoctoral fellows, and technicians. To build such a group requires grants, to obtain grants suggests you must be actively publishing, and if all of these things are happening, then tenure and promotion are moot points. So, it is still a rare individual in the sciences who succeeds solely on his or her ability to be an integral part of a collaborative group. Institutionally and nationally we need to think more strategically about whether this is indeed what we are all about.

A better model, I would contend, is the one that has grown out of the NRC funding opportunities. Faculty who are participating collaboratively and in genuine multi-disciplinary work are being rewarded with promotion, tenure, merit salary, travel opportunities and the like, despite fears that "serving two masters" in joint appointments can be "hazardous to one's academic health." I believe the scientists are moving in this direction, but I applaud the humanists and social scientists for leading the way. 